\title{
LOS PETROGLIFOS DEL CERRO BLANCO DE ZONDA (SAN JUAN)
}

\section{THE PETROGLYPHS OF CERRO BLANCO OF ZONDA (SAN JUAN)}

\author{
Alejandro García \\ CONICET (FCEFyN-UNSJ) - Facultad de Filosofía, Humanidades y Artes (UNSJ) - Facultad de Filosofía y Letras \\ (UNCuyo). E-mail: alegarcia@unsj.edu.ar
}

Presentado el: 27/07/2013 - Aceptado 23/04/2014

\section{Resumen}

Recientes investigaciones en el Valle de Zonda (centro-sur de San Juan) permitieron descubrir un conjunto de petroglifos en una de las laderas del Cerro Blanco. La mayoría de las representaciones son figurativas (antropomorfos, camélidos, huellas de aves y felinos, serpientes, etc.). Su análisis y comparación indican que al menos una parte corresponden al período Aguada local. Asimismo, se discute la posible relación del sitio con el cercano canal matriz del sistema de riego prehispánico local y su importancia en el marco del proceso de integración regional que involucró al actual territorio de San Juan desde ca. 650 d.C.

Palabras claves: Arqueología, Arte rupestre, Petroglifos, Aguada, San Juan

\begin{abstract}
During recent research in the Zonda Valley (south-central San Juan) a group of petroglyphs was discovered on one of the slopes of Cerro Blanco. Most are figurative representations (anthropomorphs, camelids, birds and felines prints, snakes, etc.). Analysis and comparison of the figures indicate that at least a portion corresponds to the local Aguada period. The possible relationship of the site with the nearby main canal of the local prehispanic irrigation system, and its importance in the context of the regional integration process involving the territory of San Juan from ca. 650 A.D., are also discussed.
\end{abstract}

Key words: Archaeology, Rock art, Petroglyphs, Aguada, San Juan 


\section{Introducción}

El arte rupestre es una de las manifestaciones arqueológicas más abundantes del territorio sanjuanino, pero en algunas zonas su estudio se encuentra en una etapa inicial. Uno de esos sectores es el Valle de Zonda, donde recientemente se descubrió un sitio con petroglifos que ha sido objeto del presente estudio. Con el mismo se espera contribuir al conocimiento y caracterización del arte rupestre del centro-sur de San Juan y promover la articulación de esta información con la conocida para otros sectores de la provincia y de esta manera ampliar las posibilidades de comprender los procesos culturales desarrollados en el área.

\section{El sitio y su entorno}

El Valle de Zonda es una pequeña depresión de forma aproximadamente triangular, flanqueada por el oeste por las Sierras Azules y por el este por la Sierra Chica de Zonda. Se extiende longitudinalmente a lo largo de 18,5 kilómetros desde el Río San Juan hacia el sur, y tiene anchos máximo y mínimo de 8,5 y $2,2 \mathrm{~km}$. El valle está rellenado por un depósito de sedimentos cuaternarios que con un adecuado riego han permitido el desarrollo de diversos cultivos que forman la base económica de la región.

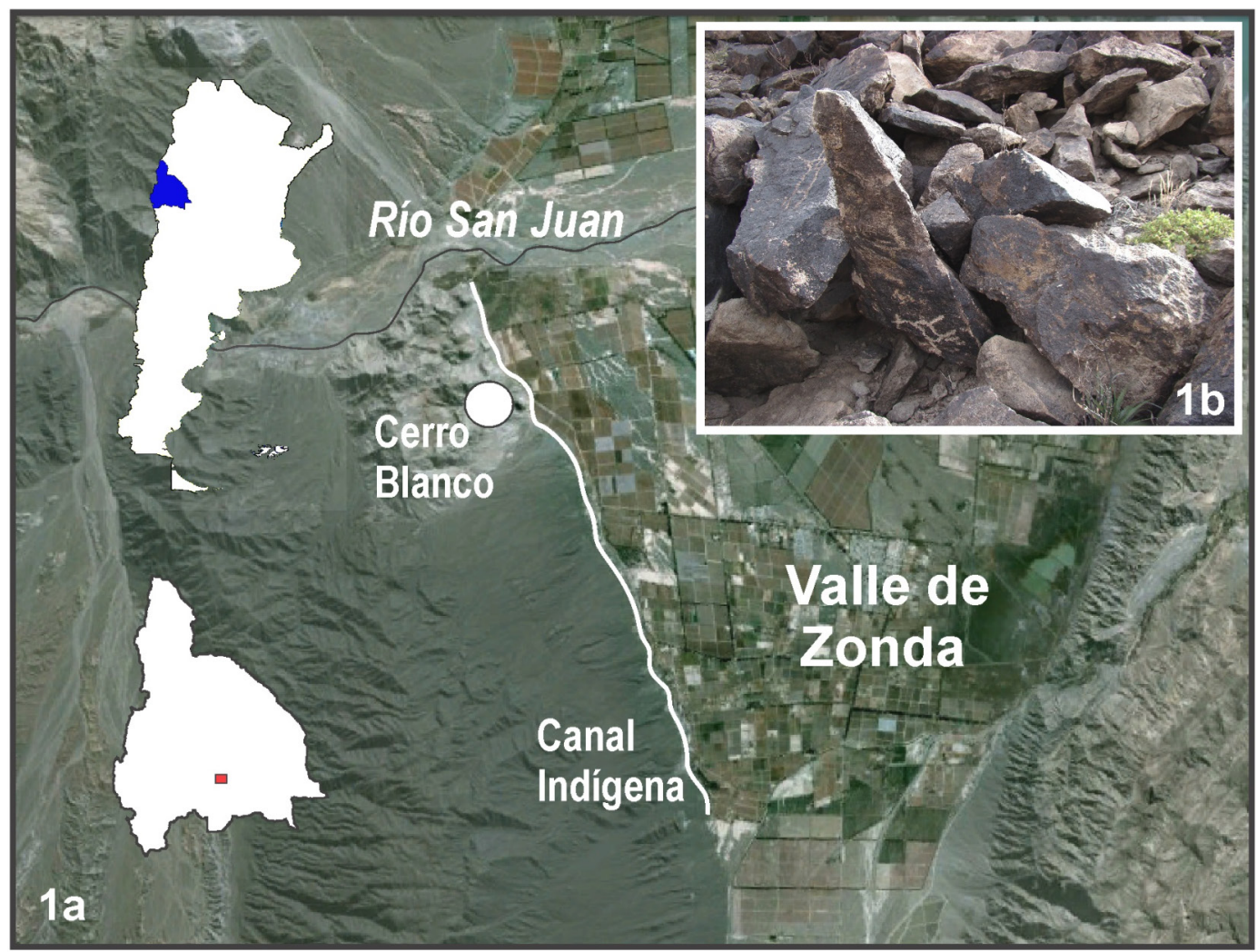

Figura 1. Ubicación de los petroglifos (punto) del Cerro Blanco (a) y posición de algunas de las rocas con petroglifos (b). En el mapa de la provincia de San Juan se indica la posición del recuadro mayor. 
Los petroglifos se encuentran en la ladera de un cerro de baja altura (850 m s.n.m.) que forma parte del conjunto conocido como Cerro Blanco, en el sector NO del Valle de Zonda (Figura 1a), a $31^{\circ} 31^{`}$ Sur y $68^{\circ} 46^{\circ}$ Oeste. Se localizaron en un área de ca. $60 \mathrm{~m}^{2}$, en el plano inclinado de la ladera del sector medio-basal del cerro.

Las figuras están realizadas en un conjunto de 17 bloques de dacita que tienen formas irregulares, con largos máximos de entre 0,8 y 1,6 m. La ubicación de algunas caras con grabados en posiciones que dificultan su visibilidad y que habrían obstaculizado en gran medida su ejecución sugiere que al menos una parte de los soportes ha sufrido leves deslizamientos y que consecuentemente el conjunto puede no guardar la relación espacial original (Figura 1b), aunque dada la integridad de los soportes se estima que esto de ninguna manera implicaría corrimientos importantes (i.e., distancias mayores a $1 \mathrm{~m}$ ). Al respecto, cabe señalar que el Valle de Zonda, al igual que el resto de la provincia de San Juan, es una zona tectónicamente muy activa (Perucca et al. 2012, Suvires 2013) por lo que es probable que la modificación de la distribución y posición de los soportes se relacione con los movimientos sísmicos locales.

No se han registrado sitios estratificados en torno a los petroglifos. Si bien se han observado algunos fragmentos de cerámica cerca de los mismos y en la cumbre del cerro, no presentan características diagnósticas que permitan establecer precisiones cronológicas o culturales. El principal rasgo arqueológico cercano al conjunto de petroglifos es un sector crítico del ya mencionado sistema de canales que corre por la margen oriental de las Sierras Azules (Damiani y García 2011).

El grupo de figuras se encuentra en una posición más alta $(c a .10 \mathrm{~m})$ y a 25 metros de distancia del Canal Matriz, en un sector en el que éste describe una cerrada curva y se dirige hacia el oeste para luego atravesar un espacio que debió ser impactado regularmente por las bajadas de agua de la serranía. De hecho, en la actualidad la zona está atravesada por dos grandes cárcavas que han destruido gran parte del Canal Matriz. Por lo tanto, en esta localización se requería un control permanente que garantizara el funcionamiento normal del sistema.

\section{Antecedentes regionales}

A pesar de su cercanía a la ciudad de San Juan (unos 25 kilómetros) y de las facilidades que tal ubicación implica para la realización de estudios arqueológicos, las investigaciones sistemáticas en el Valle de Zonda comenzaron recién hace unos años, y al presente sólo se registra una publicación específica, referida a un sistema de canales prehispánicos que corre por la margen derecha del valle (Damiani y García 2011). Este sistema, que recorre una extensión de aproximadamente 8,5 kilómetros, tomaba agua del Río San Juan a la altura del actual Cámping Municipal y la transportaba hacia el SSE por la parte baja pedemontana. El canal principal podía llevar más de 600 litros por segundo, caudal que servía para regar unos ocho núcleos de cultivo. El conjunto de canales secundarios y de regueras que completaba el sistema discurría a través de depósitos cuaternarios en cuya superficie se hallaron numerosos restos cerámicos que podrían corresponder a tiempos incaicos y tardíos preincaicos (García y Damiani 2011).

En sectores aledaños al valle y localizados dentro del departamento homónimo se han realizado algunos relevamientos de arte rupestre (Consens et al. 1991) y un inconcluso (Rodríguez y Rodríguez 2011) intento de salvataje de un conjunto de petroglifos ubicados en 
el sitio Kilómetro 53 del Río San Juan (Varela y Riveros 2001). En consecuencia, se dispone de muy escasa información contextual para relacionar el registro analizado. En relación a los estudios de arte rupestre en regiones cercanas al Valle de Zonda se cuenta con más información. Las observaciones de sitios con arte rupestre en la provincia de San Juan se remontan a principios del siglo XX (Khun 1914; Debenedetti 1917). Estudios posteriores brindaron información sobre numerosos casos correspondientes a la cordillera del oeste sanjuanino (e.g. Schobinger 1962, 1975, 1985; Gambier 1977; García et al. 2007; López y García 2011), a la precordillera (Consens et al. 1991) y Sierras Subandinas (Varela y Riveros 2004). Más recientemente se han realizado investigaciones en sitios con grabados rupestres del área de Valle Fértil (Sierras Subandinas), en el oriente provincial (e.g. Riveros y Varela 2001; Cahiza 2007; Re et al. 2009, 2011).

Con respecto al registro arqueológico Aguada, si bien se han hallado representaciones rupestres (Rusconi 1947; Re et al. 2009; García 2013; Figura 2), en ningún caso se hallaron asociadas a los sitios habitacionales (Gambier 1994, 1996-97). Los estudios de estos sitios indican que las principales características del período Aguada local incluyen la aparición de patrones rectangulares en las estructuras habitacionales, un creciente desarrollo de la agricultura y la cría de llamas, el afianzamiento del sistema de asentamiento aldeano, la utilización de tumbas monticulares, evidencias de culto al cráneo, los primeros registros de metalurgia, y algunos elementos novedosos, como la cerámica Aguada, las pipas acodadas y tembetás de botón (Gambier 2000; García 2010).

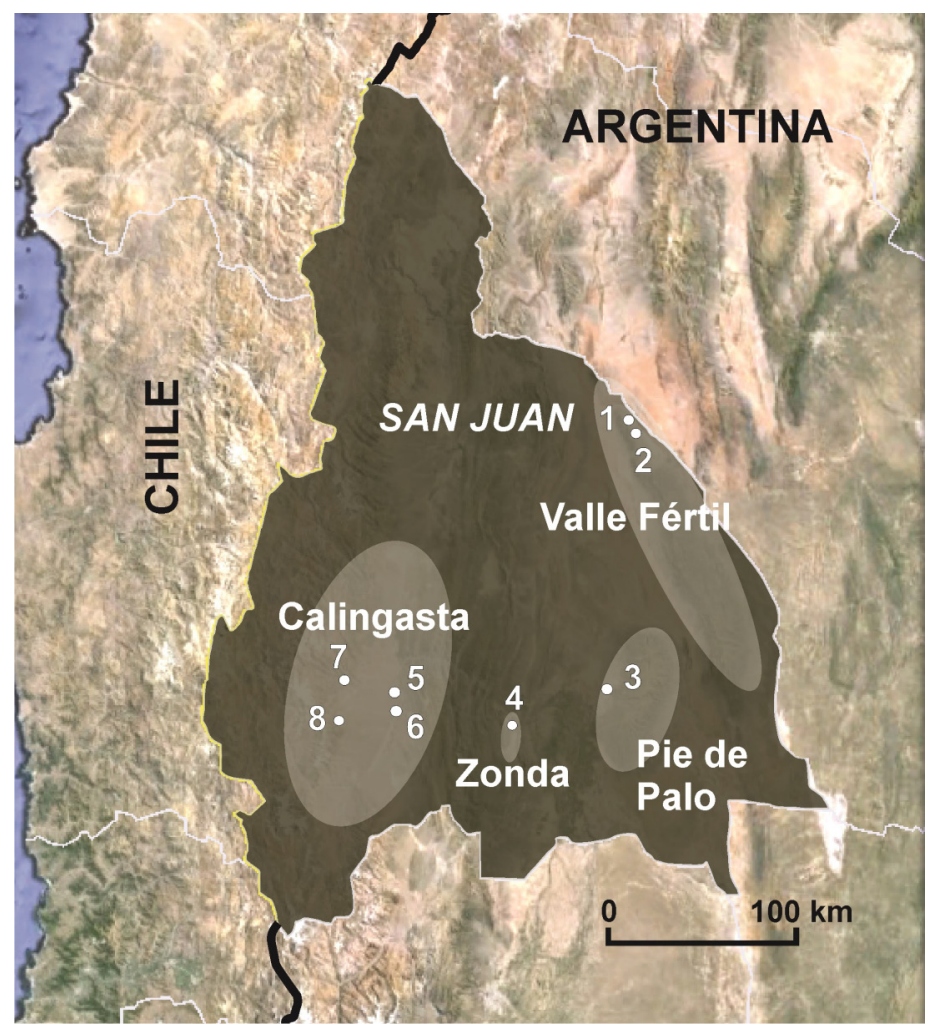

Figura 2: Ubicación de las principales zonas y sitios sanjuaninos mencionados en el texto. 1) Piedra Pintada; 2) Kiosco; 3) Quebradas del Molle Norte y Sur; 4) Cerro Blanco; 5) Los Corrales; 6) Pico Varas; 7) La Alumbrera; 8) Arroyo de los Peludos. 


\section{Descripción y caracterización de las representaciones}

Se han observado 21 superficies o caras de bloque con figuras (Tabla 1), que serán consideradas como "paneles". La mayoría presenta un solo grabado, pero en 8 casos se observan varias representaciones en una misma cara. En cinco de estas ocasiones (paneles 7, 8, 11, 15 y 19) se ha estimado que las imágenes integran una misma composición (considerada como una ordenación significativa de signos relacionados entre sí) mientras que en los otros casos, debido a la falta de relación temática o espacial dentro del panel se las ha tratado de manera independiente.

Dentro del conjunto de representaciones se observan algunas características que aparecen de manera reiterada y que brindan cierta homogeneidad a las figuras. Una de ellas es la falta de relleno de las figuras cerradas. Como puede observarse en los paneles 7,8 y 15, la representación de las figuras antropomorfas y zoomorfas se limita fundamentalmente a la silueta. Lo mismo sucede con otras figuras cerradas cuya interpretación es más difícil, como las de los paneles 3, 4, 5, 10 y 19. Comúnmente se trata de líneas relativamente delgadas y de bordes bien definidos, si bien el cuidado en su elaboración es variable. En otros casos, las representaciones son abiertas y esquemáticas, como en los paneles 1 y 9 , y a veces se reducen a simples trazos, como en los paneles 12 y 17 . Los trazos están realizados mediante picado y en general son poco profundos, y presentan espacios internos no alcanzados por los golpes y un ancho que oscila entre 10 y $20 \mathrm{~mm}$ (Figura 3). En algunos, coincidiendo con una profundidad mayor, las líneas son más regulares (como en los paneles 8 y 19). En estos casos no se observan marcas que permitan identificar la utilización de otras técnicas para la ejecución de los trazos, por ejemplo el raspado. Los tamaños de las representaciones son diversos, como puede observarse en la distribución de los módulos cuadrangulares en los que se insertan (Figura 4).

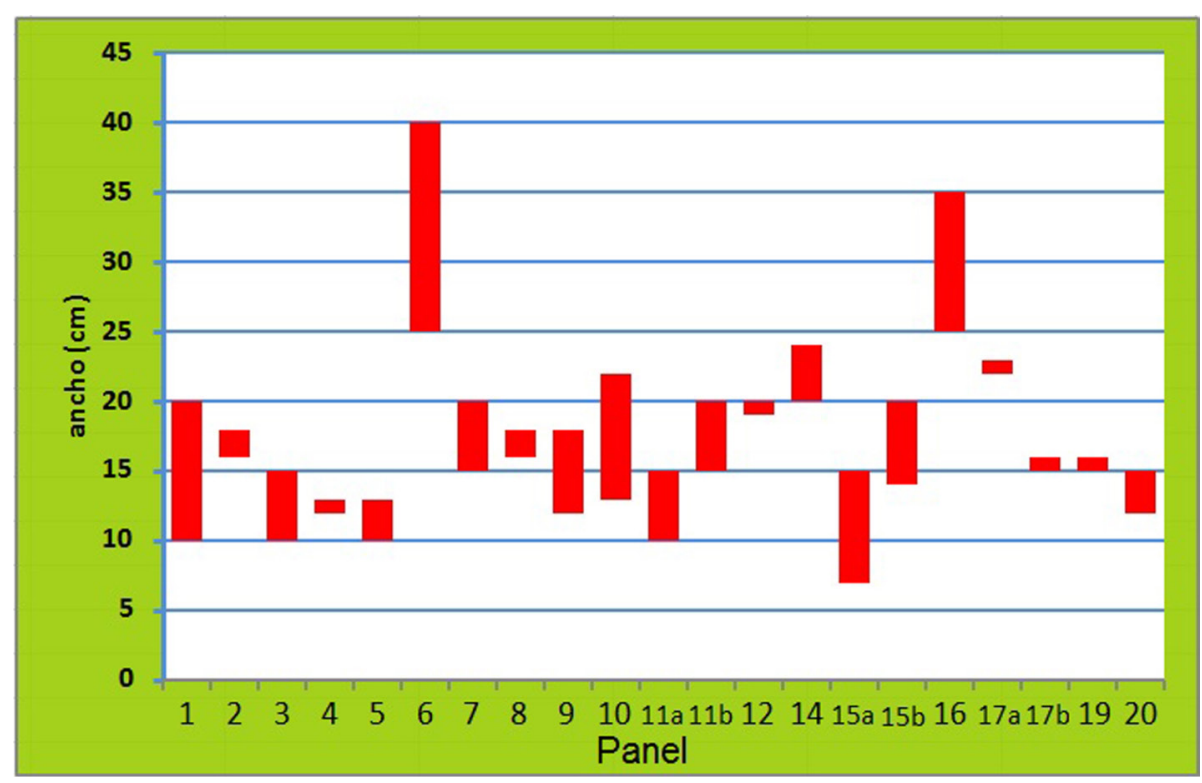

Figura 3. Ancho de los trazados en las figuras con líneas. 


\begin{tabular}{|c|c|c|c|c|c|}
\hline Bloque & Panel & Figura & Tamaño & Posición de la cara & Interpretación \\
\hline 1 & 1 & & $28 \times 20$ & Mira al S & $\begin{array}{l}\text { Figura antropomorfa } \\
\text { esquematizada }\end{array}$ \\
\hline 2 & 2 & & $23 \times 12$ & Mira al W & Serpentiforme \\
\hline 3 & 3 & 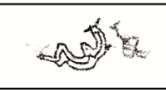 & $\begin{array}{l}37 \times 26 \\
22 \times 11\end{array}$ & Mira al SW & Serpiente \\
\hline 4 & 4 & & $8 \times 5$ & Mira al W & \\
\hline 5 & 5 & & $39 \times 18$ & Mira arriba y al W & Serpiente \\
\hline 5 & 6 & & $77 \times 18$ & Mira al E & $\begin{array}{l}\text { Serpientes con } \\
\text { cabeza felínica }\end{array}$ \\
\hline 5 & 7 & & $\begin{array}{c}50 \times 27 \\
7 \times 8\end{array}$ & Mira arriba y al S & Figura antropomorfa \\
\hline 7 & 8 & & $24 \times 22$ & Mira al S & $\begin{array}{l}\text { Camélido con posible } \\
\text { cría }\end{array}$ \\
\hline 8 & 9 & & $16,5 \times 7$ & Mira arriba & Figura antropomorfa \\
\hline 9 & 10 & & $17 \times 24$ & Mira arriba & \\
\hline 10 & 11 & $\mathrm{o}^{25 \mathrm{~m}}$ & $76 \times 27$ & Mira al N10W & $\begin{array}{l}\text { Serpientes } \\
\text { Pisada de felino }\end{array}$ \\
\hline 10 & 12 & & $20 \times 14$ & Mira abajo y al S & Pisada de ave \\
\hline 11 & 13 &  & $8 \times 8$ & Mira arriba y N10E & Pisada de felino \\
\hline 12 & 14 & & $12 \times 11$ & Mira al N80E & Pisada de ave \\
\hline 13 & 15 & ris & $\begin{array}{l}16 \times 15 \\
14 \times 11 \\
\end{array}$ & Mira al N10W & $\begin{array}{l}\text { Camélido } \\
\text { Pisada de ave }\end{array}$ \\
\hline 14 & 16 & Tr & $33 \times 32$ & Mira al N75E & Serpentiforme \\
\hline 14 & 17 & 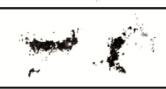 & $\begin{array}{r}10 \times 4 \\
7 \times 8 \\
\end{array}$ & Mira al S20E & $\begin{array}{l}\text { ¿Figuras } \\
\text { astronómicas? }\end{array}$ \\
\hline 14 & 18 & 8 & $\begin{array}{l}27 \times 10 \\
7 \times 6,5 \\
\end{array}$ & Mira hacia arriba & $\begin{array}{l}\text { Figura antropomorfa } \\
\text { Circunferencia }\end{array}$ \\
\hline 15 & 19 & .25 & $21 \times 21,5$ & Mira al S80E & ¿Hacha o tumi? \\
\hline 16 & 20 & th & $10,5 \times 8$ & Mira al S20E & Serpentiforme \\
\hline 17 & 21 & $8 \times *$ & $49 \times 13$ & Mira al E & \\
\hline
\end{tabular}

Tabla 1. Representaciones del sitio y distribución de los paneles. Tamaño en cm. 


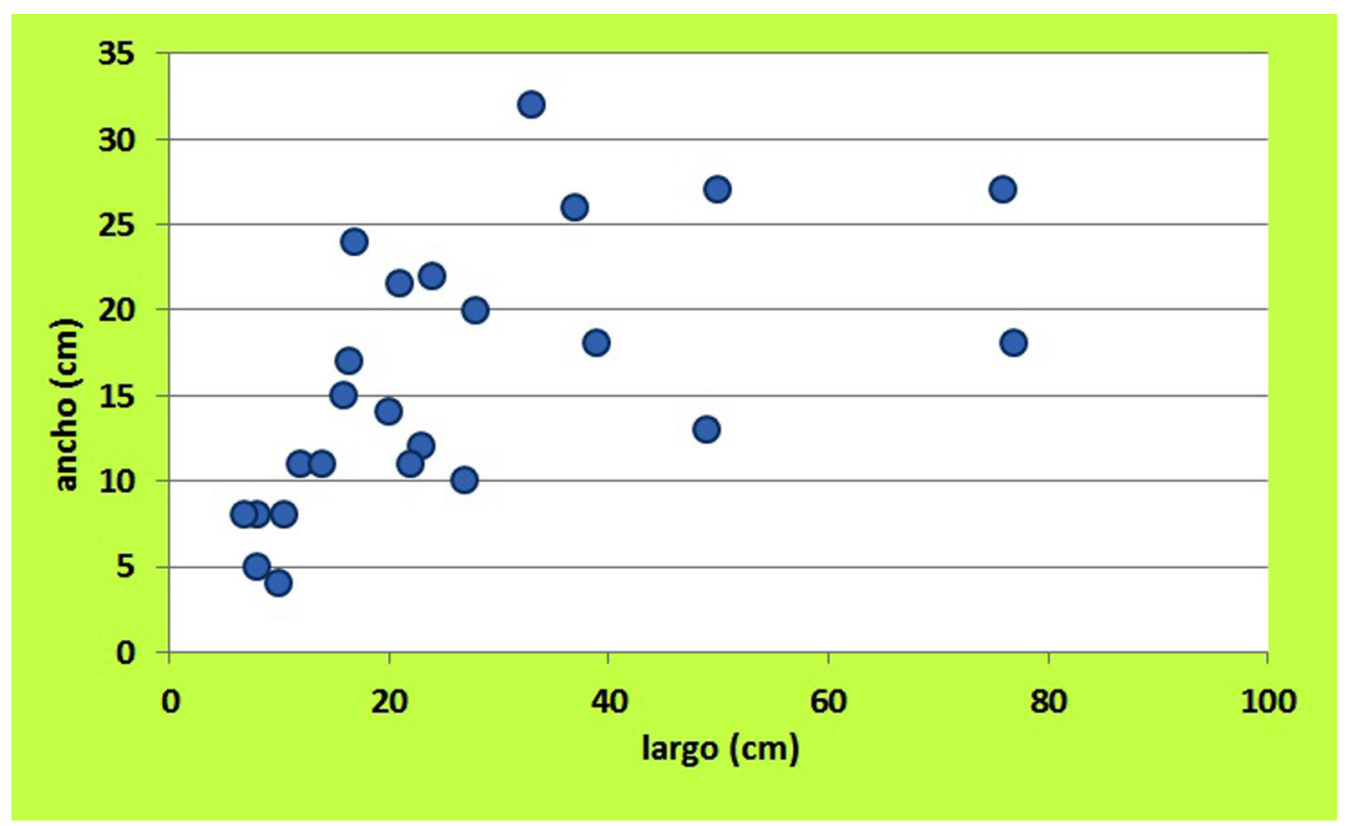

Figura 4: Distribución de los módulos de tamaño de las representaciones del sitio.

Con respecto a los motivos (Tablas 1 y 2), se destaca la representación reiterada de serpientes o serpentiformes (trazos ondulados interpretados como serpientes), que aparecen por lo menos en 7 paneles. En algunos casos se trata de figuras simples, como en los paneles 2 y 16. En otros la elaboración es mayor, como en la composición de dos serpientes enfrentadas del panel 11.

Otro elemento importante es la aparición en algunas figuras de puntos que representan manchas o pisadas de felinos (en este último caso, por su distribución en arco alrededor de un punto de mayores dimensiones), ya sea como motivo central o incluidos en otras representaciones. Así, la figura del panel 13 está formada únicamente por una pisada de cuatro puntos, mientras que las tres celdas de la representación del panel 5, que es interpretada como una serpiente, presentan 3, 1 y 4 manchas respectivamente. De la misma forma, las dos serpientes principales del panel 11 están separadas por una pisada de felino que consta de un punto de mayores dimensiones y otros 9 menores distribuidos debajo y a un costado.

Al igual que en el caso de las serpientes y serpentiformes, llama la atención la diversidad en la representación de personajes antropomorfos, desde formas más abstractas (como en el panel 1) a otras más realistas (como en el 7), pasando por la figura esquemática del panel 9. En el caso de las representaciones de camélidos cabe señalar la notable diferencia entre las figuras de los paneles 15 (silueta de perfil, abierta, con cuatro patas) y 8 (silueta de perfil, de contorno completo, con dos patas y grandes orejas).

Cabe destacar que las figuras de los paneles 5 y 11 reúnen motivos que aparecen aislados en otros paneles. En el último se observan las serpientes bien elaboradas, un serpentiforme, un trazo curvo (que podría ser interpretado como un elemento astronómico) y los puntos interpretados como una pisada de felino (que también podrían hacer alusión a las manchas 


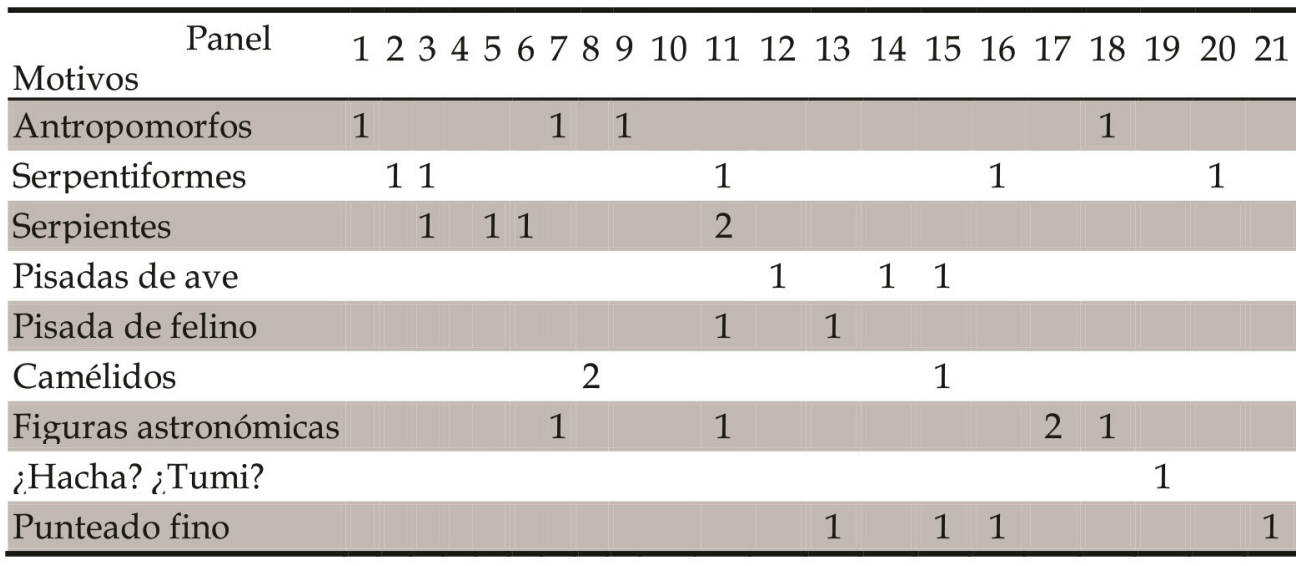

Tabla 2. Distribución de las principales figuras en los paneles del sitio (cantidad en cada panel).

del jaguar), en tanto que el primero presenta el tema de la serpiente y la utilización de puntos o manchas (Figura 5). En estos casos la reiteración y agrupación en algunas figuras de varios de los motivos registrados en el conjunto sugiere la idea de unidad temática y relativamente temporal de al menos una parte del mismo, aun cuando no existe una total uniformidad desde el punto de vista métrico (Figuras 3 y 4). En este sentido, cabe señalar que la figura del panel 6, que es la más representativa del estilo Aguada en el sitio, es la que asimismo muestra los trazos más anchos de todo el conjunto.

Finalmente, los paneles 5, 6 y 11 muestran una relación particular, ya que exhiben una asociación de elementos alusivos tanto al felino como a la serpiente, lo que indicaría la importancia de tal vinculación dentro del marco de creencias en el que se produjeron las figuras.

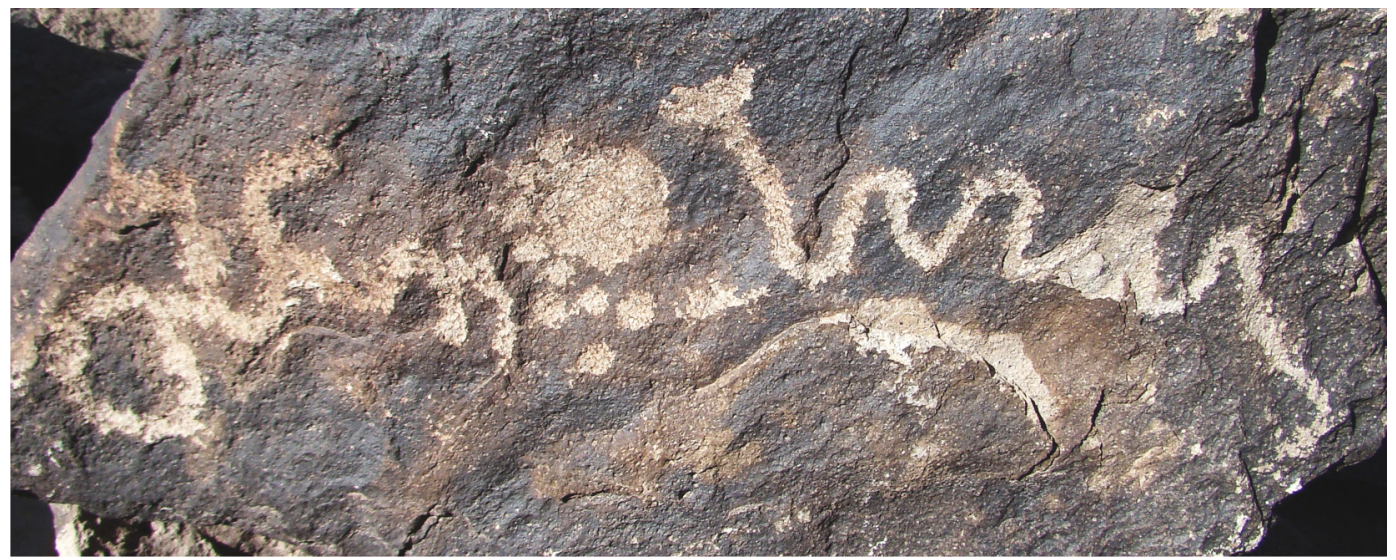

Figura 5. Dos serpientes enfrentadas, separadas por una huella o manchas de felino.

\section{Cronología y adscripción cultural}

No se observan elementos técnicos que indiquen claramente diferencias importantes en la elaboración de las figuras. Como ya se ha señalado (García y Damiani 2011), no aparece ninguna representación atribuible a tiempos hispano-indígenas, y la única que 
podría tentativamente vincularse con el período incaico es la que recuerda la silueta de un tumi (Tabla 1, panel 19). Sin embargo, no se cuenta con elementos objetivos que permitan establecer diferencias de cronología en el conjunto de grabados.

Con respecto a las pátinas, las observaciones indican que las diferencias de color en el interior de los trazados de las figuras responden fundamentalmente al grado de extracción de la misma en cada sector. Por lo tanto, como lo que reflejan tales diferencias es el proceso de cambio reductivo (pérdida de masa) en la pátina por extracción (Bednarik 2002), las pátinas en el sitio no son indicadores confiables de cronología relativa.

En consecuencia, la única forma de identificar alguna diacronía en el conjunto o su posible antigüedad es la comparación formal de las representaciones a nivel local (del valle y sectores aledaños), regional (otros sectores dentro de la provincia) y extrarregional. Los resultados positivos de dicho cotejo se exponen a continuación.

Panel 1. Se trata de una figura antropomorfa con las extremidades representadas con líneas curvas o volutas (Figura 6), las que aparecen también en otros sitios de la región (si bien en una posición diferente y a veces en la cabeza). Los apéndices de la parte superior no sólo son similares a los de la figura del panel 7 sino que también han sido registrados en otros sitios de la región, como Los Colorados y La Alumbrera, ambos en el piedemonte cordillerano del Valle de Calingasta.

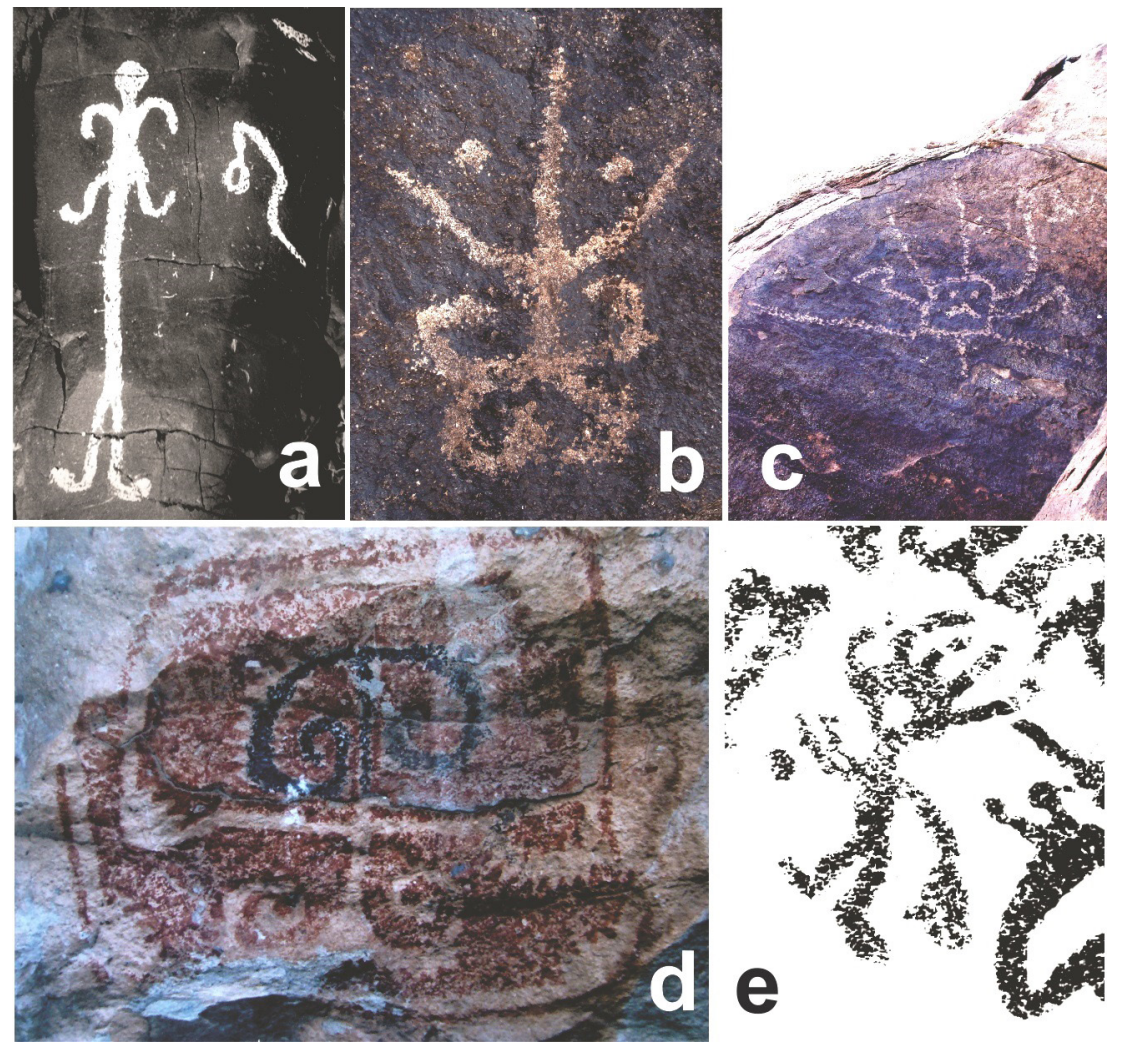

Figura 6. Representaciones antropomorfas con volutas o líneas curvas como extremidades, y con apéndices en la cabeza. a) Km 53, Zonda. b) Cerro Blanco. c) Los Colorados, Calingasta. d) Los Morrillos, Calingasta. e) La Alumbrera, Calingasta. 
Panel 5. Este grabado está formado por una secuencia de celdas romboidales con puntos en su interior y con una especie de cola en un extremo y de pequeña cabeza con dos apéndices en el otro. Las figuras con múltiples celdas, a veces con puntos o manchas en su interior, aparecen en sitios del Valle de Calingasta como La Alumbrera, Los Corrales y Pico Varas, y se ha propuesto que este tipo de elementos correspondería al período Aguada local (García 2013). La figura del panel 5 parece representar una serpiente esquemática y las manchas en su cuerpo corresponderían a las del jaguar, como en el caso de la túnica de San Pedro de Atacama (Figura 7; Llagostera 1995: 20).
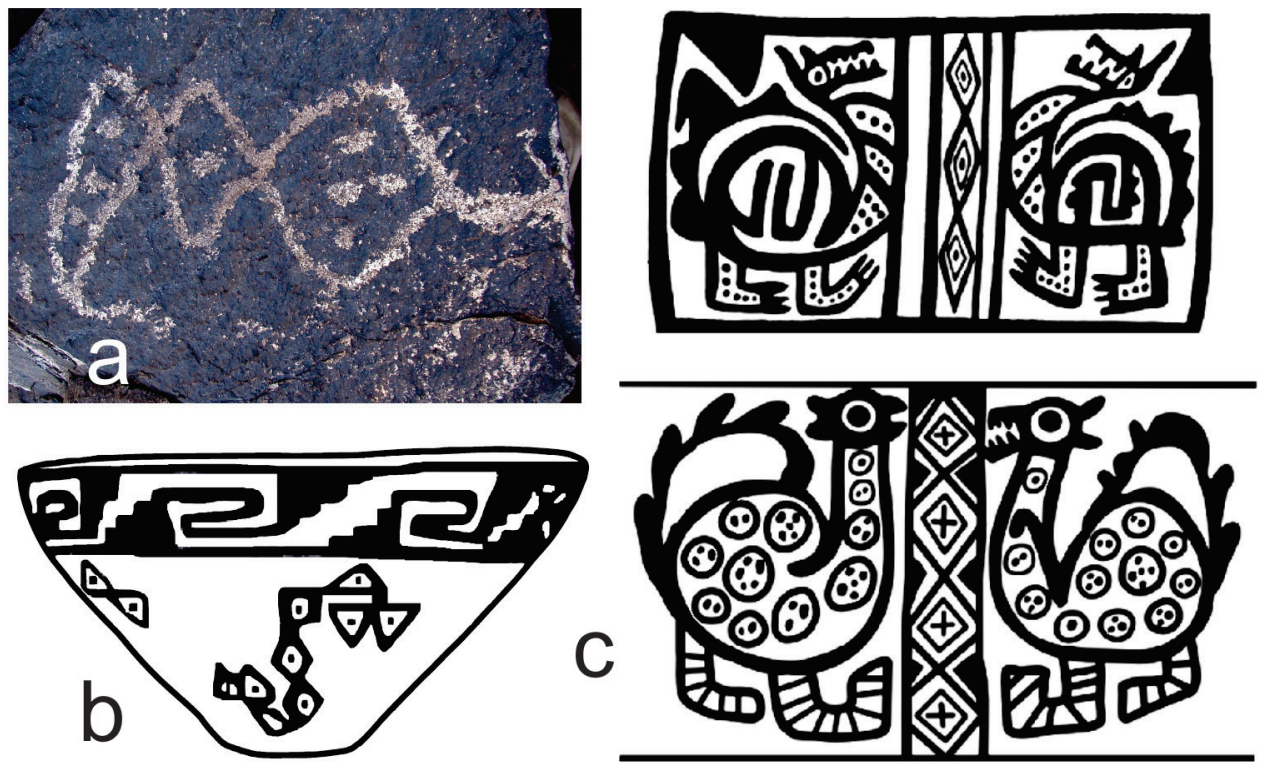

Figura 7: Ejemplos de animales felinizados: a) Grabado del panel 5 de Cerro Blanco. b) Serpiente geométrica en un recipiente cerámico del sitio Las Mojarras, Catamarca. c) Suris felinizados en una vasija del sitio Punta de Balasto, Catamarca. B y c tomados de Reynoso y Pratolongo (2008).

Al respecto, cabe recordar que la felinización se observa también en otros animales, como los suris o ñandúes de la cerámica santamariana del Valle de Yocavil (Reynoso y Pratalongo 2008). Esta utilización de algunos atributos representativos del jaguar se vincula con "la forma que adquieren los procesos de atomización y recomposición en el estilo" (Kusch 1991: 14). Uno de los resultados de estos procesos puede ser el uso de una parte o rasgo de una figura como medio de reemplazo de toda la imagen. Esto significa que "un elemento determinado (por ejemplo las garras) remite a toda la figura principal a la que pertenece y lo que ella representa conceptualmente (el felino)" (Kligmann y Díaz País 2007: 51). En el caso del panel 5, esto estaría sucediendo con las manchas felínicas en el cuerpo de la serpiente.

Panel 6. Este es el caso que muestra una relación más clara con las figuras Aguada del NOA (Kligmann y Díaz País 2007). Consiste en la representación de una anfisbena con rasgos felínicos (mandíbulas y orejas), que ocupa la porción central de una de las caras del bloque 6 (Figura 8). Este tipo de figuras, vinculadas con el período Aguada o de Integración Regional, aparece en diferentes soportes en algunos sitios del NOA y del norte de Chile, como La Toma I (arte rupestre; Llamazares 1993: 36), Puerta del Corral Quemado (arte rupestre, Lorandi 1996), Los Algarrobales 2 (arte rupestre; Gordillo y Calomino 210: 254), La 

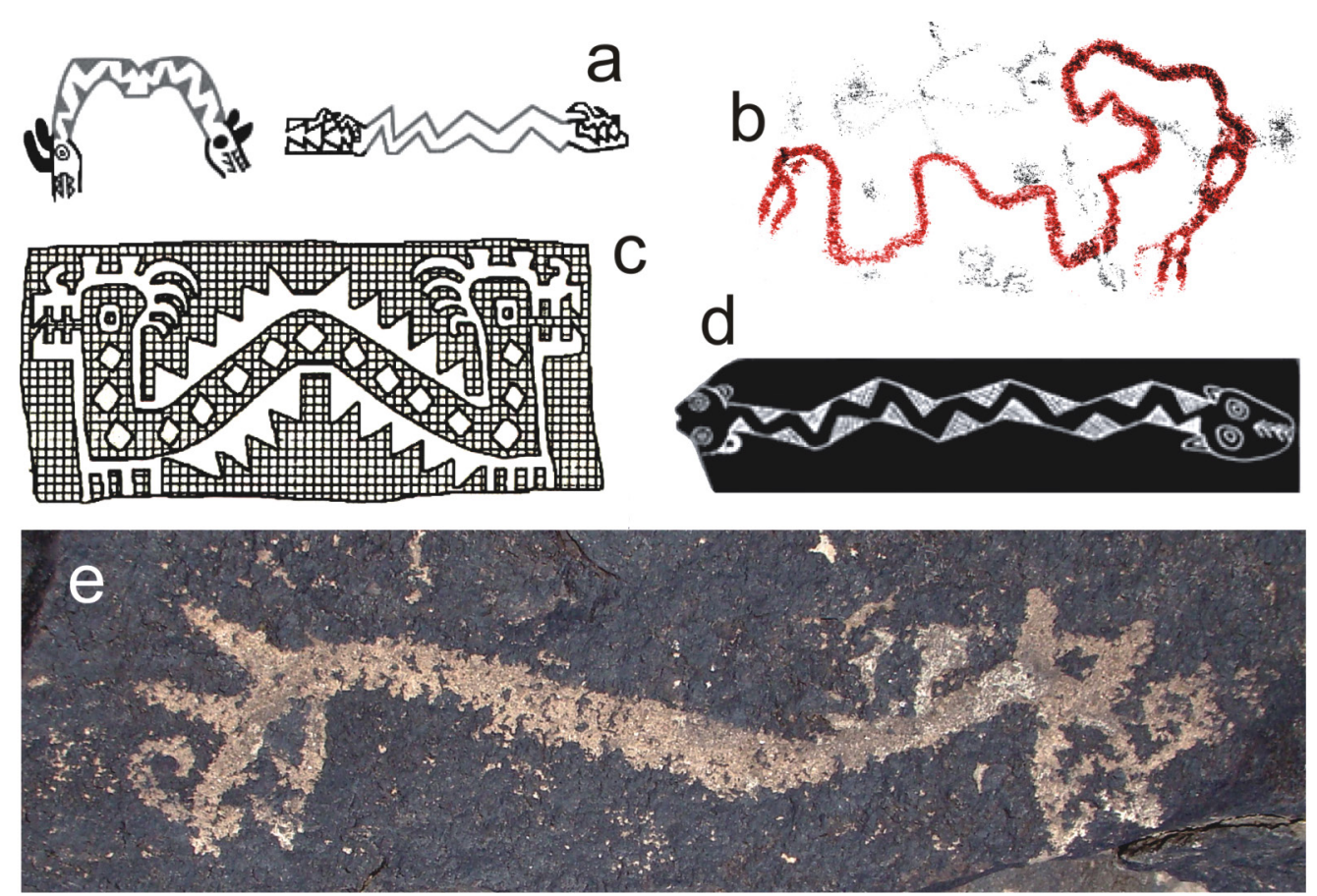

Figura 8. Diversas representaciones de anfisbenas vinculadas con el período Aguada. a) tomada de Kligman y Díaz País 2007; b) sitio Los Corrales; modificada de García 2013; c) tomada de Llagostera 1995; d) tomada de Gordillo 2008; e) panel 6 de Cerro Blanco.

Rinconada (cerámica, Gordillo 2009: 109) y San Pedro de Atacama (textil, Llagostera 1995: 19). Una representación de la serpiente con dos cabezas en los extremos se encuentra en el cercano valle de Calingasta, en el sitio Los Corrales.

Panel 7. Presenta una imagen antropomorfa esquemática, de cuerpo cerrado sin relleno (Figura 9). Figuras similares se han hallado en algunos sitios de Catamarca, como El Overito, donde fueron relacionadas con el Formativo Medio -Aguada- de la subárea valliserrana (Korstanje y Aschero 1996: 205), y en Peña del Indio y Piedra Pintada (de Hoyos y Lanza 2000), donde no tiene una asignación cronológica precisa. A nivel regional se encuentran figuras similares en conjuntos en los que aparecen representaciones que han sido vinculadas con el período Aguada local, como en Arroyo de los Peludos 1 y 4 (García 2012) y Los Corrales (García 2013).

Panel 9. La figura antropomorfa de este panel no tiene características morfológicas que permitan una asignación directa, pero resulta interesante el hecho de que en la mano izquierda parece llevar una cabeza humana (Figura 10), situación que ya se ha observado en el sitio Los Corrales, donde ha sido vinculada con el período Aguada local (García 2013). Esta representación podría constituir una versión regional de la figura del sacrificador, presente en el arte rupestre (De la Fuente y Arrigoni 1975; Callegari et al. 2009: 393; Nazar et al. 2012: 303-304) y en soportes cerámicos Aguada (González 1961-1964: 215; Gordillo 2009: 107).

Paneles 11 y 13: Además de la representación de dos serpientes enfrentadas que constituyen las figuras principales de la escena, en el panel 11 se observa una gran huella de felino en medio de ambas. En el panel 13 aparece otra versión de la huella felina, en esta ocasión 




Figura 9. Representaciones de antropomorfos de silueta cerrada y vacía. a) Panel 7 Cerro Blanco; b) de Korstanje y Aschero 1998; c) de Hoyos y Lanza 2000; d) sitio Los Corrales (Calingasta, San Juan); e) Arroyo de los Peludos (Calingasta, San Juan).

con cuatro puntos. Este motivo tiene una amplia distribución en sitios del NOA (e.g. Falchi et al. 2011: 45; de Hoyos y Lanza 2000: 127). En San Juan se lo ha observado en diversos sitios de la Sierra de Valle Fértil, como Piedra Pintada-El Salto, Kiosco, Piedras de Ontivero y Puerta de las Quebradas (Re et al. 2009: 424), y en la Sierra Pie de Palo -sitios Quebrada del Molle Sur y Quebrada del Molle Norte (Riveros 2001, Varela 2001). Sin embargo, este motivo tiene una dispersión espacial muy amplia y lo mismo podría suceder con su cronología, por lo que en realidad no resulta representativo en sí mismo para realizar comparaciones, sino en función de su relación con otros. En todos los casos arriba señalados se han observado también motivos abstractos y figurativos (por ejemplo, antropomorfos) pero sus formas difieren significativamente de las registradas en el Cerro Blanco.
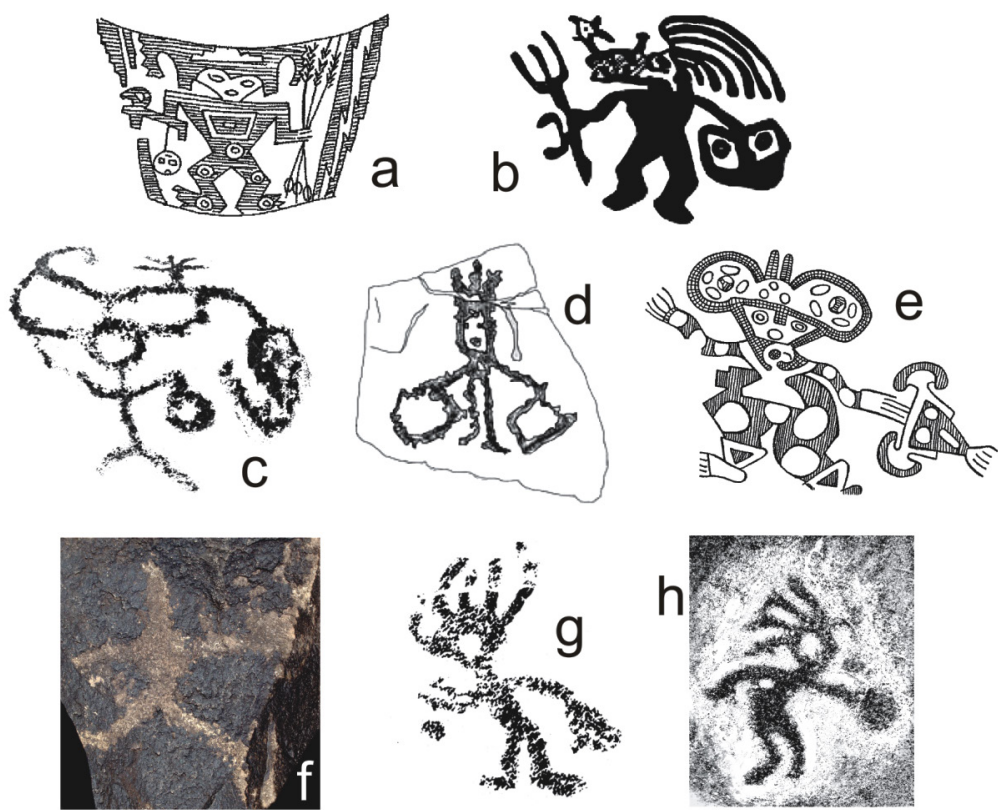

Figura 10. Figuras de personajes que sostienen cabezas en sus manos. a), tomado de González 1961-1964. b) La Tunita, tomado de LLamazares 1993. c) Los Corrales, tomado de García 2013. d) Cerro La Marca, tomado de Callegari et al. 2009. e) Vasija cerámica de Ambato, tomado de González 1998. f) Cerro Blanco. g y h) La Alumbrera, Calingasta. 
En el conjunto analizado se observan otras figuras que en el Valle de Calingasta han aparecido asociadas con representaciones del período Aguada, como la circunferencia del panel 18, los trazos curvos en forma de medialuna (paneles 7, 11 y 17) y los tridígitos de los paneles 14 y 15, ya registrados, por ejemplo, en los sitios Quebrada de las Piedras Pintadas, Pico Varas y Los Colorados, todos en el Valle de Calingasta (García 2013). Esto no significa que tales motivos sean típicamente "Aguada" sino que su reiterada asociación con elementos de ese período es congruente con la adscripción otorgada a varias de las figuras del Cerro Blanco.

En síntesis, por lo menos varios de los motivos analizados (algunos de los cuales no presentan antecedentes en la arqueología de San Juan) corresponderían al período Aguada local. Lo mismo sucede con diversos hallazgos realizados tanto a nivel local como regional (Figura 11). En las cercanías del Valle de Zonda, en el Palque de Pachaco (a ca. $50 \mathrm{~km}$ de distancia del valle), se halló una roca con una de sus caras completamente grabada, que presenta entre otras figuras un antropomorfo alado, un felino y varios motivos serpentiformes (Schobinger 1975). Por otra parte, en el Museo Enzo V. Manzini, ubicado en el propio Valle de Zonda, puede observarse un antropomorfo similar en un petroglifo proveniente de la localidad (García et al. 2008). En la Quebrada de Agua Blanca, en el Valle de Iglesia, se ha registrado un petroglifo que contiene algunas imágenes asignadas al período Aguada, en las que se destaca un personaje con garras en los pies y ataviado con una capa de jaguar (López y García 2011). Por el contrario, en el sector oriental sanjuanino y en la Sierra Pie de Palo no se han hallado representaciones que puedan inequívocamente vincularse con el período Aguada (Riveros 2001; Varela 2001; Podestá et al. 2006; Cahiza 2007; Re et al. 2011), con la posible excepción de un lagarto felinizado que se registró en el sitio Piedra PintadaEl Salto (Re et al. 2009).
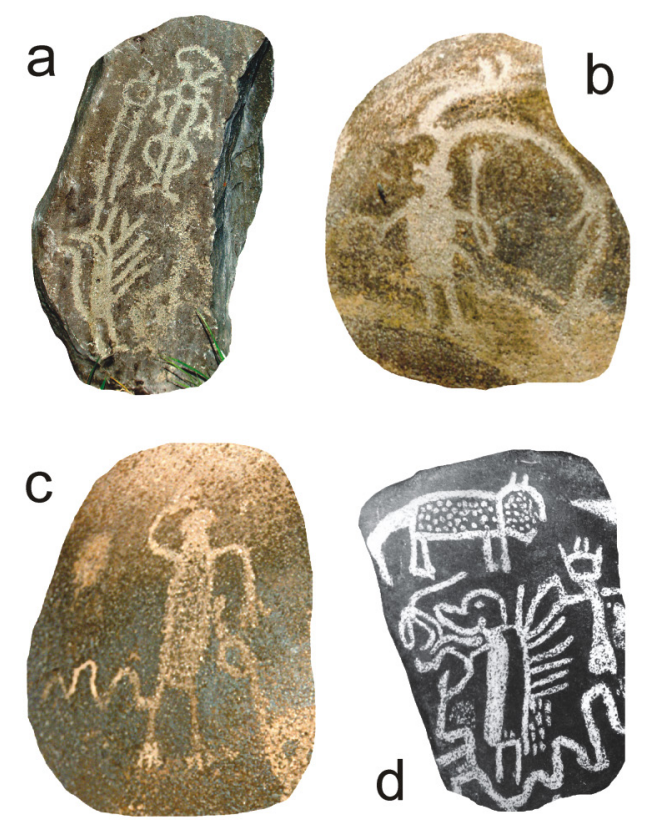

Figura 11. Figuras antropomorfas de otros sitios de la región. a) Zonda (Museo E. Manzini); b y c): Quebrada de Agua Blanca. d) Palque de Pachaco (Zonda). 


\section{Discusión}

Si bien el conjunto analizado es relativamente pequeño, ofrece la posibilidad de realizar algunas consideraciones sobre su localización, su relevancia y el uso de los soportes.

Relación con el agua. Con respecto a la ubicación del sitio, cabe señalar que las dimensiones de los bloques (ver Figura 1b) habrían permitido su transporte, lo que sugiere que la localización de los petroglifos en ese lugar no se debe simplemente a la presencia de los soportes sino a la elección deliberada de ese punto para establecer las imágenes. Sin embargo, a pesar de ser un lugar abierto, este emplazamiento no presenta características especiales ni asociaciones particulares que lo justifiquen, y en realidad la visibilidad de los petroglifos desde la base del cerro es casi nula.

La estrecha cercanía con el Canal Matriz del sistema de riego prehispánico de la zona sugiere que la explicación de tal emplazamiento es precisamente la conexión espacial entre ambos registros arqueológicos. De hecho, las figuras no parecen estar dispuestas para ser fácilmente reconocidas desde el nivel de base, desde los costados o desde el canal, sino todo lo contrario: para observar y controlar desde su posición el normal funcionamiento del canal en un sector crítico, dados el marcado cambio de dirección y el riesgo de destrucción por la bajada de agua, rocas y sedimento en eventos pluviales fuertes desde la parte alta del cono de deyección correspondiente. En este sentido, los petroglifos estarían marcando un lugar clave para el desenvolvimiento del sistema ( $\mathrm{y}$ en definitiva, de las poblaciones que dependían del normal aprovisionamiento de agua), y algunas de sus representaciones posiblemente formaran parte de algún ritual vinculado con esa función de control y resguardo, y consecuentemente, con la garantía político-religiosa de estabilidad de las condiciones de vida de esos grupos. Esta asociación directa de grabados rupestres con cursos de agua (en este caso, un canal) ya ha sido observada en varios casos en el oeste de San Juan (e.g. Tocota, Agua Blanca, Conconta y Arroyo de los Peludos) y posiblemente denota el particular interés por reflejar el dominio y manejo de este recurso y su probable importancia en el marco del sistema de creencias de la época. En este sentido resulta clave la reiterada aparición de la serpiente como figura ligada a los cursos de agua, que posiblemente no sólo evoca la vinculación de ambos elementos sino también la forma de los canales y de algunos cauces naturales. Al respecto, un caso interesante es el del panel 3 (Tabla 1), cuya figura principal no sólo podría ser interpretada como la vista superior de una serpiente sino también como la de una corriente de agua que fluye por su correspondiente cauce.

Cabe consignar que si bien la relación entre el Canal Matriz y el sitio con petroglifos es fundamentalmente espacial, la posible correspondencia de aquél al período Aguada esta también sustentada por el relleno de casi $1 \mathrm{~m}$ de sedimentos laminados (depositados durante su utilización) que presenta en algunos sectores y que le confiere una antigüedad bastante mayor que la del momento de cese de funcionamiento del sistema. A juzgar por la cerámica observada en superficie esto habría ocurrido en tiempos de la conquista española (García y Damiani 2013); la ausencia de cerámica Aguada en superficie puede deberse tanto a su localización en niveles estratigráficos sub-superficiales como a la intensa acción antrópica que tradicionalmente ha afectado esta zona y que generalmente se vincula con un levantamiento selectivo de materiales cerámicos. 
Los bloques con múltiples paneles. La elección de algunos soportes para la realización de figuras en varias de sus caras no parece responder a una ubicación o posición especial con respecto al resto, ya que las mismas no les otorgan un lugar central ni mayor visibilidad. No obstante, se observa una significación relativamente especial de las figuras allí grabadas. En efecto, en el caso de la roca con tres paneles (16, 17 y 18, en el Bloque 14) se destacan la imagen simple (vista superior) de una serpiente y de un posible antropomorfo (acompañado por una circunferencia), en tanto resulta muy difícil evaluar la relevancia de los otros motivos (dos líneas curvas, que posiblemente estén vinculadas con las fases lunares). Más destacado resulta el caso del Bloque 5, que constituye el soporte de los paneles 5, 6 y 7, ya que involucra dos de las figuras más elaboradas del sitio (la anfisbena y un antropomorfo), cuyas cabezas se conectan a través de uno de los apéndices del último. Además, como ya se ha señalado, la imagen del panel 5 (Figura 7) parece una vista superior de una serpiente cuyo cuerpo estaría formado por celdas o compartimentos con puntos, elementos característicos de otros conjuntos Aguada de San Juan (García 2013). Por lo tanto, el aprovechamiento de múltiples caras de un mismo bloque podría tener una relevancia particular por la asociación de determinados motivos, aunque esta posibilidad sólo podrá ser mejor evaluada en el futuro, a la luz de un mayor conocimiento de otros casos a nivel regional.

El registro Aguada en San Juan. Finalmente, otro aspecto importante es la contribución de los estudios de arte rupestre para una mejor comprensión del período Aguada local. La presencia de una parte de la iconografía Aguada en el Valle de Zonda es un indicador más del alcance espacial de los cambios ideológicos ocurridos entre ca. 650 y 1100 d.C. en varios sectores del territorio, ya comprobados en diversos sitios habitacionales y en otros con representaciones rupestres de los valles de Jáchal, Iglesia y Calingasta (García 2013), al oeste y norte del espacio provincial, y posiblemente también en la parte oriental (Re et al. 2009, 2011). Estas innovaciones abarcan la utilización de cerámica Aguada fundamentalmente en los valles de Calingasta, Iglesia y Jáchal (Debenedetti 1917; González 1967) -pero también en Valle Fértil (Guráieb et al. 2010; Re et al. 2011)-, la adopción de nuevos diseños y materiales constructivos para las estructuras habitacionales (Gambier 1996-1997, 2000), y la implementación de patrones funerarios novedosos para la región (Gambier 1994, 1996-1997), que incluyen por un lado el entierro de cuerpos sin cabeza, y de cabezas aisladas por el otro (Gambier 2000). Debido a su magnitud, estos cambios han sido interpretados como el resultado de una "invasión" del territorio sanjuanino por parte de grupos del NOA (Gambier 2000). Sin embargo, esta gran dispersión espacial también podría reflejar un proceso de adopción de nuevas creencias, tecnologías y repertorios iconográficos por parte de las poblaciones ya asentadas en estos valles, como parte de la intensa articulación que desde hacía siglos se venía desarrollando con las sociedades del sector meridional del Noroeste argentino (García 2010). En otras palabras, constituiría una manifestación más de una integración regional producida por la interacción de diversos grupos humanos. Como resultado de esa interacción existiría una superestructura (ideológica) común, pero "en cada región las manifestaciones concretas van a ser diferentes, según los antecedentes históricos y culturales de cada región, y de la misma forma, a nivel de organización social, pueden alcanzar distintos grados de desarrollo, según las regiones" (Nuñez Regueiro y Tartusi 1990: 153) ${ }^{1}$. Desde esta visión, y aun cuando esa superestructura no haya sido homogéneamente compartida por las sociedades involucradas, podría considerarse que las representaciones analizadas constituyen un reflejo local de la misma y muestran variaciones específicas en el tratamiento de algunos motivos, como las serpientes felinizadas y el sacrificador. 
En este sentido, el arte rupestre ofrece la posibilidad de registrar las eventuales variaciones iconográficas que puedan observarse en los repertorios del período Aguada en distintas zonas de San Juan, y por lo tanto constituye una perspectiva importante para comprender mejor los procesos culturales desarrollados en el territorio sanjuanino desde ca. 650 d.C.

\section{Comentarios finales}

Los estudios desarrollados por Gambier en la década de 1990 demostraron la fuerte conexión de diversas regiones del oeste y norte de San Juan con los procesos que se desarrollaron desde la segunda mitad del primer milenio d.C. en el NOA, y que están especialmente representados por el fenómeno "Aguada". Los actuales estudios en el Valle de Zonda sugieren que el arte rupestre fue otro de los medios de difusión de la iconografía Aguada en el territorio sanjuanino, a la vez que extienden el escenario geográfico del período Aguada local a la zona de los valles precordilleranos y abre expectativas acerca de su futura búsqueda en el aún inexplorado Valle de Tulum (donde se encuentra actualmente la ciudad de San Juan), en el corazón del área huarpe.

\section{Notas}

1 No existe acuerdo acerca del origen y características del fenómeno Aguada. El alcance de las articulaciones referidas, el grado de integración de las sociedades involucradas, el papel de la iconografía en este proceso, y el desarrollo de condiciones de diferenciación social y centralización política son algunos de los aspectos discutidos en los últimos años (Cruz 2006, Scattolín 2006, Laguens 2006, Gordillo 2009, 2012, etc.). Fundamentalmente, estos estudios han revelado un grado de heterogeneidad mucho mayor que el implicado por las propuestas integradoras de fines del siglo XX (Pérez Gollán y Heredia 1990, Núñez Regueiro y Tartusi 1990).

Agradecimientos: Los trabajos realizados en el Valle de Zonda han sido financiados por el CONICET (PID N 1870), la UNSJ y la UNCuyo. Las fotografías de Los Morrillos y Km 53 de la Figura 6 fueron amablemente proporcionadas por el señor Antonio Beorchia Nigris. Agradezco las oportunas sugerencias de Anahí Re y Susana Carrizo y de los dos evaluadores anónimos. Un reconocimiento especial para Andrea Recalde por su interés y sus valiosos comentarios a una versión anterior del manuscrito.

\section{Bibliografía citada}

Bednarik, R.

2002. The Dating of Rock Art: a Critique. Journal of Archaeological Science 29: 1213-1233.

Cahiza, P.

2007. Una perspectiva espacial para el estudio de las representaciones rupestres de Valle Fértil (Provincia de San Juan). Cuadernos del Instituto Nacional de Antropología y Pensamiento Latinoamericano 21: 253-258.

Callegari, A., L. Wisnieski, G. Spengler, G. Rodríguez y S. Aumont

2009. Nuevas manifestaciones del arte rupestre del oeste riojano. Su relación con el paisaje y con otras expresiones del arte Aguada. Crónicas sobre la piedra. Arte Rupestre de las Américas (ed. por Sepúlveda, M., L. Briones y J. Chacama), pp. 381-402. Ediciones Universidad de Tarapacá, Arica-Chile. 
Consens, M., A. Castellano y C. Dibueno

1991. Análisis de rasgos en el arte rupestre del Río San Juan. El arte rupestre en la arqueología contemporánea (ed. por M.M. Podestá, M. I. Hernández Llosas y S. F. Renard de Coquet), pp. 92-100. Salón Gráfico Integral S.R.L., Buenos Aires.

Cruz, Pablo

2006. Complejidad y heterogeneidad en los Andes meridionales durante el Período de Integración Regional (siglos IV-X d. C.). Nuevos datos acerca de la arqueología de la cuenca del río de Los Puestos (Dpto. Ambato, Catamarca, Argentina) Bulletin de l'Institut Français d'Études Andines, 35 (2): 121-148.

Damiani, O. y A. García

2011. El manejo indígena del agua en San Juan (Argentina): diseño y funcionamiento del sistema de canales de Zonda. Multequina 20: 27-42.

Debenedetti, S.

1917. Investigaciones arqueológicas en los valles preandinos de la Provincia de San Juan. Publicaciones de la Sección Antropología, 15. Facultad de Filosofía y Letras, UBA, Buenos Aires.

De Hoyos, M., y M. Lanza

2000. Arte rupestre en San Antonio del Cajón, Provincia de Catamarca. Relaciones de la Sociedad Argentina de Antropología XXV: 119-144.

De la Fuente, N. y B. Arrigoni

1975. Arte rupestre en la región sudeste de la provincia de Catamarca. Actas y Trabajos del Primer Congreso Nacional de Arqueología Argentina, pp. 177-203.

Falchi, M.P., M.M. Podestá, D.S. Rolandi, A. Re y M.A. Torres

2011. Arte rupestre entre las sierras y los llanos riojanos: localidad arqueológica Palancho. Comechingonia, Revista de Arqueología 15: 39-63.

Gambier, M.

1977. La Cultura de Ansilta. IIAM, Universidad Nacional de San Juan, San Juan.

1994. La Cultura de la Aguada en San Juan I. Ansilta 7:14-19.

1996-97. La expansión de la Cultura de La Aguada en San Juan. Shincal 6: 173-192.

2000. Prehistoria de San Juan. Ansilta, San Juan.

García, A.

2010. Arqueología Prehistórica de San Juan. EFU, San Juan

2012. Representaciones rupestres en la cuenca del río Ansilta (San Juan). Presentado a las V Jornadas Arqueológicas Cuyanas. Mendoza.

2013. Relevamiento de sitios con representaciones rupestres en el valle de Calingasta (San Juan). Arqueología y Etnohistoria del Centro-Oeste Argentino (comp. por A. Rocchietti, M. Yedro y E. Olmedo), pp. 89-100. Unirío, Río Cuarto.

García, A., N. Fernández, O. Damiani, C. Jofré, A. Carrizo, A. Eguaburo y C. Cabello 2007. Relevamiento arqueológico del área del Parque Nacional San Guillermo y zonas adyacentes. Diversidad biológica y cultural en los Altos Andes Centrales de Argentina. Línea de Base de la Reserva de Biosfera San Guillermo -San Juan- (ed. por E. Martínez Carretero), pp. 225-250. Inca Editorial, Mendoza. 
García, A., O. Damiani y C. López.

2008. La arqueología del Valle de Zonda. Zonda, un oasis para soñar (ed. por S. Manzini de Adárvez y Y. Quiroga), pp. 51-57. Archivo General de la Provincia. San Juan.

García, A. y O. Damiani

2013. Acercamiento preliminar a la cronología del sistema de canales de Zonda (San Juan). En Arqueología y Etnohistoria del Centro-Oeste Argentino (comp. por A. Rocchietti, M. Yedro y E. Olmedo), pp. 101-109. Unirío, Río Cuarto.

González, A.

1961-64. La Cultura de la Aguada del NO Argentino. Revista del Instituto de Antropología II-III: 203-253.

1967. Una excepcional pieza de mosaico del N.O. argentino. Etnia 6: 1-28.

1998. Cultura La Aguada del Noroeste Argentino (500-900 d.C.) 35 años después de su definición. Arte Precolombino. Cultura La Aguada. Arqueología y Diseños. Filmediciones Valero, Buenos Aires.

Gordillo, I.

2009. Dominios y recursos de la imagen. Iconografía cerámica del Valle de Ambato. Estudios Atacameños 37: 99-121.

2012. Eso que llamamos Aguada. Su lugar en la historia de las investigaciones arqueológicas del Noroeste Argentino. Trabajo presentado al Simposio Arqueología del Periodo Formativo en Argentina: Un encuentro para integrar áreas y sub-disciplinas, revisar significados y potenciar el impacto de las investigaciones en curso. Tafí del Valle, Tucumán. Disponible en ecaths1. s3.amazonaws.com

Gordillo, I. y C. Calomino

2010. Arte rupestre en el sector septentrional de la Sierra El Alto-Ancasti (Dpto. El Alto, Catamarca). Actas del VIII Simposio Internacional de Arte Rupestre: 251-255. Tucumán.

Guráieb, A. G., M. Rambla y D. Carro

2010. Primera aproximación al estudio del registro lítico y cerámico del Parque Provincial Ischigualasto (PPI). Arqueología del Centro Oeste argentino: aportes desde las IV Jornadas Arqueológicas cuyanas (ed. por R. Bárcena), pp. 91-105. INCIHUSA, Mendoza

Kligmann, D. y E. Díaz País

2007. Una primera aproximación a los motivos serpentiformes de la iconografía Aguada del NOA. Intersecciones en Antropología 8: 49-67.

Korstanje, A. y C. Aschero

1996. Arte rupestre en los valles El Bolsón y Las Cuevas (Catamarca, Argentina). Formulando hipótesis de cambio y conflicto. Chungara 28 (1 y 2): 199-222.

Kuhn F.

1914. Estudios sobre petroglifos de la región diaguita con un croquis y varias láminas según fotografías. Revista de la Universidad de Buenos Aires XXV: 385-391.

Kusch, F.

1991. Forma, diseño y figuración en la cerámica pintada y grabada de La Aguada. El Arte Rupestre en la Arqueología Contemporánea (ed. por M.M. Podestá, M. I. Hernández Llosas y S. F. Renard de Coquet, pp. 14-24. Salón Gráfico Integral S.R.L., Buenos Aires. 
Laguens, A.

2006. Continuidad y ruptura en procesos de diferenciación social en comunidades aldeanas del valle de Ambato, Catamarca, Argentina (s. IV-X dC.). Chungara 38 (2): 211-222.

López, C. y A. García

2011. Análisis preliminar de los petroglifos de la Quebrada de Agua Blanca. Arqueología y Etnohistoria del Centro-Oeste Argentino (comp. por C. Mayol Laferrère, F. Ribero y J. Díaz), pp. 363-374. Universidad Nacional de Río Cuarto, Río Cuarto.

Lorandi, A.

1996. El arte rupestre del Noroeste argentino. Dédalo 11(4): 15-72.

Llagostera, A.

1995. El componente cultural Aguada en San Pedro de Atacama. Boletín del Museo Chileno de Arte Precolombino 6: 9-34.

Llamazares, A.

1993. El arte rupestre de los parajes La Tunita y La Toma, ladera oriental de la Sierra de Ancasti, Catamarca. Ms. disponible en http//www.desdeamerica.org.ar/word/ LaTunitayLaToma.pdf

Nazar, D., L. Gheco y C. Barot

2012. Avances en la documentación del sitio La Tunita (Catamarca, Argentina). Comechingonia 16:299-308.

Nuñez Regueiro, V. y M. Tartusi

1990. Aproximación al estudio del área pedemontana de Sudamérica. Cuadernos 12: 125-160.

Pérez Gollán, A. y O. Heredia

1990. Hacia un replanteo de la cultura de La Aguada. Cuadernos 12: 161-179.

Perucca, L., G. Lara y N. Vargas

2012. Nueva evidencia de actividad tectónica cuaternaria en la depresión Zonda-Maradona, Provincia de San Juan. Revista de la Asociación Geológica Argentina 69 (1): 97-105.

Podestá, M., D. Rolandi, A. Re y O. Damiani

2006. Arrieros y marcas de ganado: Expresiones de arte rupestre de momentos históricos en el desierto de Ischigualasto. Tramas en la Piedra. Producción y Usos del Arte Rupestre, (ed. por D. Fiore y M. M. Podestá), pp. 169-190. WAC, AINA, SAA y Altuna Impresores, Buenos Aires.

Re, A., M. M. Podestá y D. Rolandi

2009. Arte rupestre prehispánico en valles y quebradas del Parque Provincial Ischigualasto y su área de amortiguación (Provincia de San Juan, Argentina). Crónicas sobre la piedra. Arte rupestre de las Américas (ed. por M. Sepúlveda, L. Briones y J. Chacama), pp. 413-419. Universidad de Tarapacá, Arica.

Re, A., M. M. Podestá y G. Romero

2011. Ocupaciones humanas y grabados rupestres del norte de la Sierra de Valle Fértil (provincia de San Juan). Comechingonia 15: 65-92. 
Reynoso, A. y G. Pratalongo

2008. Jaguares de nuevo. Consideraciones sobre la temática felínica en la iconografía cerámica del período Tardío en Yocavil (Noroeste Argentino). Estudios Atacameños: Arqueología y Antropología Surandinas 35: 75-96.

Riveros, G.

2001. Análisis del arte rupestre de la quebrada del Molle Sur (Depto. Angaco, San Juan). Publicaciones 25: 3-44.

Riveros, M. G. y A. Varela

2001. Ischigualasto: Estudio preliminar del arte rupestre. Publicaciones 25: 131-147.

Rodríguez, N. y A. Rodríguez

2011. Gestión y manejo de los bienes patrimoniales arqueológicos de la provincia de San Juan: el caso de los petroglifos del Km 53 (Zonda). Al comienzo del camino (coord. por A. Eguaburo, N. Rodríguez y A. Rodríguez), pp. 133-146. EFU, San Juan.

Rusconi, C

1946. La Cueva Pintada del Lagarto (San Juan). Anales de la Sociedad Científica Argentina CXLII: $49-61$.

Scattolin, M. C.

2006. Contornos y confines del universo iconográfico precalchaquí del valle de Santa María. Estudios Atacameños 32: 119-139.

Schobinger, J.

1962. Representaciones de máscaras en los petroglifos del occidente argentino. Anthropos 57: 683-699.

1975. Experiencias psíquicas y cultos esotéricos reflejados en el arte rupestre sudamericano. Actes du Symposium International sur les Religions de la Préhistoire: 491-498. Edizioni del Centro, Capo di Ponte.

1985. Área de los pastores y agricultores andinos (Puna, Valles y Quebradas del Noroeste argentino, Región Cuyana). Arte rupestre de la Argentina. Cazadores de la Patagonia y agricultores andinos (ed. por J. Schobinger y C. Gradín), pp. 50-79. Encuentro Ediciones, Madrid.

Suvires, G.

2013. Geomorfología tectónica y evolución del relieve en un sector del piedemonte occidental de la sierra Chica de Zonda, Precordillera Oriental, Argentina. Revista Mexicana de Ciencias Geológicas. Disponible en http:/ / satori.geociencias. unam.mx/

Varela, Adriana

2001. Petroglifos de la Quebrada del Molle Norte (Dpto. Angaco, San Juan). Análisis Estético. Publicaciones 25: 45-130.

Varela, A. y G. Riveros

2001. Rescate de los petroglifos del Río San Juan (KM 53). Publicaciones 25: 148-151.

2004. Arte rupestre de San Juan: petroglifos de Angaco (obra abierta en el espacio y el tiempo). Chungara 36(2): 663-671. 